\title{
Virtual collaboration tools used in project management learning: case study in the Amazon Forest area
}

\author{
A. C. Stanger ${ }^{1} \&$ A. F. de Abreu $^{2}$ \\ ${ }^{1}$ Department of Mathematic and Statistic, \\ Federal University of Acre, Brazil \\ ${ }^{2}$ IGTI, Federal University of Santa Catarina, Brazil
}

\begin{abstract}
The use of collaborative and cooperative tools has been widely accepted in distance learning environments, where they are often used. This article presents a case study developed from the use of collaborative tools with the objective of assisting the Projects Management course of the Information Systems degree, in the Federal University of Acre. This university is part of the public system education, located in the Amazon Forest area, far from the large technological centres in Brazil and with limitations with regards to infrastructure and technological resources. Despite being a Information Systems course, the diagnosis identifies the limited use of technological resources as support to the classes and activities of the course and the lack of use of technology as resource for the communication between students and professors. The methodology for the development of this research was based on the use of virtual free tools for the creation of a group where files and messages were exchanged between the participants. Projects management activities had been undertaken in a seminar form, and two projects, an individual monographic work and another work, undertaken in groups, as a business project. The results show the importance of a frequent interaction between students and professor, agility, flexibility, large use of the information technologies and communication, integration between students and cooperation in the exchange of information and materials. The experience shows the viability of the application of this methodology, through the use of freely available tools on the Internet. The paper concludes that the use of models based on the cooperation, collaborative and interactive activities allows the development of important skills that can be used in other contexts through the collective communication between professors and students.
\end{abstract}

Keywords: collaborative groups, Project Management, computer-support, cooperative work, communication, interaction, Internet tools. 


\section{Introduction}

The collaborative environments have been applied to exchange local information and also to permit interaction between distant people and have predominantly used as solutions for distance learning, where the learning environment is supported by the collaboration and cooperation between technologies. However, it was verified that these tools have been used to carry out tasks and to solve collaborative problems, especially where the individual abilities can be combined to produce works and projects of quality. (Brito et al. [1])

According to Turoff and Hiltz [2], when a work is developed in a project form, as opposed to the work of an individual, there is a management aspect and this can have better results than the work of an individual, as the ideas can be refined through constructive criticism and suggestions.

This research project was elaborated with the objective to introduce collaboration tools in a conventional face-to-face learning environment to provide a better interaction, availability of teaching material and to promote a process of teaching/learning beyond the classroom.

In addition, this research approach is supports the belief that the technology alone is not the only component that influences the quality of education, but that it needs to be used in a planned critical way, according to the context.

This research was made in a public university, in an environment with resource restrictions and with the objective to improve the course and to make it more attractive to the students as well to use Information Technology as a support to the educational activities.

The research tried to verify the possibility to implant mediation settings of the technology to extend the alternatives of face-to-face learning with the introduction of a new virtual context that, when articulated in a strategic way, add values to the traditional models of education.

\section{Case study}

The area of research in collaborative and cooperative environments has been presented as a subject of academic interest, and also of interest to organizations and the society in general, that perceive the opportunities that the use of these environments can provide. The utilization of these tools focus in the use of computers for the cooperation between people, requiring abilities related to the virtual environments as well the respect of certain rules such as those present in real communities.

This article presents a case study developed in the area of collaborative environments at the course Management of Projects, in the Federal University of Acre, located in the state of Acre, part of the Amazon Forest area. Despite being far from the large centres of technology in Brazil, and with restrictions relating to finance and technology resources, the university offers a degree in Information Systems. In this environment, professors experience many problems teaching courses relating to technology and computers use. 
The Projects Management course is offered in the last year, when the students already have certain autonomy in their learning. The main objective of this course is to qualify the students in projects management in Information Technology, as well in projects related to software development, monograph projects and project to relating to a Technology Company.

Despite it being an Information Systems course, notice that there is a limited use of technological resources as a support to the class and course activities and also there is use of technology as a communication tool.

Considering the problems presented, this paper presents an attempt to make the course more attractive through the use of free technological resources available on the Internet.

\subsection{Methodology}

For the development of the course a virtual space was created where teaching material could be made available and where students and professors could communicate. For the choice of the environment it was required that it should be free, easy to learn and simple to access. For this reason it was decided for a virtual collaboration environment called "groups" from the company Yahoo!Brazil® which satisfied all the required conditions.

This environment has the functionalities to work properly as a message area, chat room, space for files and pictures, and a space designed to publish links of interest, as well for the creation of databases, surveys and diaries.

After the creation of the group, the functionalities presented were tested and the students informed that they must register to access them. Restricted access by password was chosen to give privacy and to prevent access by people not connected with the course. From the 32 students enrolled in the course, 26 of these were effectively participating and registered in the group.

Despite the limitations of the size of the collaboration space a tool was offered to allow chat and also the use of instant messages programs to permit communication between students and professor in real time.

After that was proposed to the students the development of two projects: the first one refers to the monograph project that in agreement with the university rules should be done in an individual form and must to be related to technology. The second, was the creation of a technological company project, to stimulate their entrepreneur capacity for the reason of the few opportunities in the local job market.

Besides the utilization of the collaboration environment to publish messages and news, a mechanism was created to follow the partial works deliveries, using a ranking, that used "colourful tokens" system: green being used for the deliveries in the closing date, orange for the deliveries after the stipulated date, and red for the undelivered cases. Also, a questionnaire was used for the final assessment of the course.

\subsection{Development}

The course was developed in 4 phases, as follows. 


\subsubsection{Project theory}

In the first phase, the study is based on a teaching material elaborated by the professor and disposed in the area of files of the collaboration environment, basing itself on the work of Bruzzi [3], Cleland and Ireland [4], Dinsmore [5], Heldman [6], Kerzner [7], Maximiniano [8] and Vargas [9]. In this material were treated the concepts such as types, characteristics, scope, history and benefits of the projects management. Also, the main causes of success and failure in projects were shown as well the current myths about project management.

\subsubsection{Monograph project}

The second phase, about the monograph project, was also based in teaching material that was elaborated using part of the theory of Silva and Menezes [10], being the original work disposed in the area of files.

The dynamic of this phase occurred during the classes, where the professor displayed the theoretical contents, followed by a stipulated date to deliver a project with the subject worked on in class. This process was repeated 5 times, with 5 versions of the project presented by the students.

The methodology used for the assessment of the versions was as follows: the students did the upload of the document in the area of files and the collaborative environment sent an automatic message to the professor notifying the date and schedule of this inclusion. These messages were used to control the order of delivery as well to decide if the deliveries were inside the closing date or not. Next, according to the order of delivery, the professor performed the evaluation using the resources of "comments" and "highlight" available in the revision tools of the Microsoft Word $\AA$, and exchange the document received in the area of files with the new file with comments. Consequently, for each new version the suggested corrections were added in the previous phase and new items added. The time stipulated between each delivery was about 15 days.

\subsubsection{Seminar}

The third phase of the course was made in a parallel form to the two previous phases and was a seminar about "Projects Management in information technology", based in the homonym work by Prado [11]. This teaching material was used as base for the seminaries for the reason that it treats the subjects in an objective way and also to represent low cost, in comparison with others books. Despite to be used as base for seminaries, the students were motivated to seek extra information to improve the presentations.

The methodology used to guide the seminar was the division of the group in 5 teams. Based in previous experiences about seminaries, notice the presence of problems as: a) the team often only having interest in the subject that will be presented by themselves; b) the teams, concerned about their own presentation, do not to pay attention in the others seminaries; c) there is little participation of the students at the presentations because the reading is not sufficient to apprehend the subject.

In order to avoid these common problems in seminar's activities, a methodology was developed where all students had access to the complete 
material of the other teams. Next, the chapters of the material were divided in five parts a raffle was drawn for the topic and presentation order.

For the presentation of the seminar the following methodology was used, previously informed between the students: while a team presented the content, the second team should ask a question about the presented subject to the third team, which should answer the question according to the context. The fourth team would make a criticism about the content and the fifth and last team should make an evaluation about the content and the presentation of all previous teams. This process was done until all teams experienced the whole situation, as observed on the Table 1 below:

Table 1: $\quad$ Seminar dynamics.

\begin{tabular}{|l|c|c|c|c|c|}
\hline & 1st. Seminar & 2nd Seminar & 3rd Seminar & 4th Seminar & 5th Seminar \\
\hline Team 1 & Present & Evaluate All & Criticise & Answer & Ask \\
\hline Team 2 & Ask & Present & Evaluate All & Criticise & Answer \\
\hline Team 3 & Answer & Ask & Present & Evaluate All & Criticise \\
\hline Team 4 & Criticise & Answer & Ask & Present & Evaluate All \\
\hline Team 5 & Evaluate All & Criticise & Answer & Ask & Present \\
\hline
\end{tabular}

The first seminar focused on the importance to administrate the information technology, what is Information Technology (IT) project, history of the projects management, the PMI (Project Management Institute) and the concept of PMP (Project Management Professional) certification and how to obtain it. (Dinsmore [5], Heldman [6], Kerzner [7], Prado [11]).

The second seminar was about the information technology projects life cycle, the phases, process and the areas of knowledge or management action, which are: integration, scope, time, costs, quality, human resources, communications, risks and procurement. At this opportunity also was explained the critics success factors (CSF) in projects of IT. (Heldman [6], Maximiniano [8], Prado [11]).

In the third seminar was presented the project managers, their contributions, responsibilities, formation and experience. In addition, this seminar treated the question of the action plan divided between resume and details of the project and the management and strategic considerations. Finally, how to use the Gantt graphic, PERT diagram, financial and physical schedule and graphic resources to help the action plan were approached (Kerzner [7], Prado [11]).

The fourth team was responsible for talking about the risks analysis in projects, to follow the execution, modifications control in projects with its management tools as reports, Gantt graphics, anomalies analysis, vulnerabilities analysis etc. (Cleland and Ireland [4], Prado [11]).

The fifth and last group was responsible for talking about the planning and quality control in projects during its life cycle, drawing parallels with the question of the quality control in other areas beyond the utilization of standard as ISO-9001 for the software development area. This group also mentioned the way to implant the projects management in the organizations, offices projects creation 
(PMO - Project Management Office) and the utilization of computerized tools as MS-Project, Spring, Artemis, Cplan, TimeLine etc. (Dinsmore [5], Prado [11]).

\subsubsection{Technology company project}

The fourth phase of the course was the creation of the technology company project, based on the knowledge previously acquired and students were free to choose different kinds of business. The only demand is that it should be a technology company.

For the development of this activity there was no specific orientation about how to proceed and each team could find out the necessary requirements for the company opening. The professor didn't supply any project model or script to be followed. The given orientation was that they should use the seminar material and a computerized tool for the elaboration of the project.

As a result of the poor condition of the computer laboratories and the poor bibliography available at the library, it was suggested that the students could create a "project office". The professor also disposed in the collaboration environment a sort of material related with the subject.

After the elaboration of the projects, the teams presented the companies projects. The criteria adopted for the evaluation was the utilization of the course contents and the viability of the idea of business for the area.

\subsection{Results}

Based on the research, it was verified in a empirical way that some students, even being from the Information Systems course, didn't have an email account and those that did, did not have the habit to check their postal boxes daily.

In the beginning, several students experienced difficulties accessing the collaboration environment, because most of them did not have Internet access or the required ability to create a login and a password. However, after some days, with the availability of the teaching material only in that environment, the students were forced to access the site in a continuous way.

Another difficulty verified was that the students did not have familiarity in using the communication tools. Some of them, even with the possibility to access instant messages tools did not know how to use it and especially how to obtain benefits to improve their knowledge and to create communication between their colleagues and professor. It was observed that the students had difficult to solve some problems, becoming dependent of the professor, even with the whole material available in the collaboration environment and the web to research about their interest topics. The big problem was that the students did not know how to deal with the technology in an efficient way, losing time using it with other purpose like chat at any time, forgetting to give focus for the main purpose of the project. However, these problems were solved later with the establishment of some rules.

\subsubsection{Messages}

The messages tools were one of the most used in this collaboration environment. In comparison with the work developed in the previous year, its was verified a 
growth of more than $200 \%$ in the volume of traffic messages, considering a horizon of time of 4 months against 8 months of the previous year.

The messages sent to the group by the professor had the objective to notify modifications in the calendar, reading suggestion, absence control, notices related to the projects management, etc. The messages from the students were not only about this course but also were used for other courses, due to the absence of other communication channels in the university.

\subsubsection{Files}

The area of files was the most utilized by the students, therefore it was in this space that were disposed the material of the course to download as well to the upload the works from the students. For this purpose, specific folders for the storage of projects, classes material, extra-class contributions, seminaries material were created and also an area called "playground" where were disposed files that treated the projects management in a funny way, like jokes and messages of motivation. The participants were allowed unlimited access to all the folders and most of all students used to contribute with the material disposed there.

\subsubsection{Database}

The area of database was used for three distinct purposes: to obtain information about the students, about their monographs, and also about the companies' project.

The first table created was to insert information about the students, like name, birthday, email address, cell phone and place of work. This table was filled by $88 \%$ of the students that effectively participated of the course.

The second table was created to obtain information about the students monograph. In this table were created fields for the name of the student, the adviser, topic of research, delimitation of the topic and the kind of monograph (theoretical work, case study, software development, etc.). This table was filled by $73 \%$ of the students.

Finally, the third table, had fields to insert the name of the company, the action area, the team components, the presentation date of the project and date of presentation of the seminar. This table was filled by $80 \%$ of the students.

\subsubsection{Survey}

In the beginning of the semester were created two surveys to know the initial motivations of the students about the development of the course.

The first survey treated the question of the projects management, to find out if the students had some previous knowledge about the subject. From the total, $50 \%$ took part with the result that $46 \%$ were found to already know a little about the matter and would like to go deeper through the subject; 39\% did not know but also had interest in the matter and $15 \%$ had already heard about. There were no answers for the following choices: a) did not know the matter; b) know the matter in a deep way; c) had already worked with projects before.

The second survey treated specifically the question of the monograph project for the conclusion of the degree and had as objective to find out if the students 
had already defined topic and adviser. This survey was answered by $50 \%$ of the students, where $84 \%$ already had topic and adviser, followed by $8 \%$ of the answers that had topic but not adviser and $8 \%$ also had some ideas but didn't have defined the topic.

\subsubsection{Chat, pictures, links and diary}

As regard to the other available tools in the collaboration environment, chat, pictures and diary were not used regularly. Only the link area received some contributions with addresses about thesis bank, projects management, PMI, Information Systems courses and computer classes' society.

\subsection{Evaluation}

At the end of the semester, a questionnaire was disposed for the evaluation of the course and created a standard login and password for all students, to give transparency and to permit the anonymity in the answers, that should be sent to the professor's email and to avoid that the answer of a student influenced others.

From the total of 26 students registered in the group 35\% answered the questionnaire, in a period of 3 days. From this total, $67 \%$ of the answers were from male and $33 \%$ female, with ages about 23 years old. Despite only $78 \%$ of the students have computer, everybody had email and use it very often and also has Internet access at home or at work (78\%) and eventually at the university. Most of the students that answered the questionnaire had access to more than one instant messages program.

Even though only $33 \%$ of the students had already experienced a collaboration group, they didn't find problems to use it. As a result, there was an increase of $56 \%$ in the email access, attributing as main advantages the agility in the communication (100\%), closeness with the professor $(67 \%)$ and between the students $(22 \%)$, and agility in the problems solving $(56 \%)$.

The Information Technology tools used in the other courses were considered inadequate in $89 \%$ of the students' answers, being aimed few courses that make sporadic use of simple tools as email and material in digital format.

The computer lab is rarely used by the students; only in situations that they cannot access in other places. The library has also a sporadic use, due to the outdated books and not representing the current state of the technology area.

The seminar had a high rank of satisfaction for everybody, with $44 \%$ very satisfied and $56 \%$ satisfied, not having any negative evaluation. This satisfaction occurred mainly because the used methodology in the seminar, approved by $67 \%$ of the students, and also due to the individual participation, where $56 \%$ of them affirmed to have participated more than in other similar activities.

About the classes' dynamics, $89 \%$ of the students approved, mainly by the fact of to be able to participate in a more active talked class. The method of assessment in the course also was approved for the totality of students, especially because the way that the course was guided in class, electing creativity with $67 \%$ of the assessments and dynamism with $56 \%$.

The online monograph project evaluation was approved for $100 \%$ of the students, aiming as the main advantages the speed of sending (78\%) and also the 
economy by not being necessary to print the project $(67 \%)$. The main difficulty pointed about the project elaboration was the writing followed by the definition of the topic (22\%) and the researching (22\%).

Regarding the company project, there were contradictory opinions where $44 \%$ of the students enjoyed the activity because they felt stimulated to find out by themselves the suitable software for the project, against $44 \%$ that did not like and the others didn't answer. Despite the belief that students from the $7^{\circ}$ semester are autonomous in their studies $(67 \%)$, the main problem pointed was the question that there was not a model to be followed. The management used in the conduction of this project was: team management $(67 \%)$, project management $(44 \%)$ followed by the time management, scope and others.

Finally, they were asked questions to answer in a subjective form about the satisfaction regarding to the course and this verified the approval by $100 \%$ of the students, being pointed subsequent studies in the area and the indication of the methodology used should be extend to the other courses aiming to making the degree more interesting, collaborative, as well the suggestion to create a communication channel to provide the approach between students and professors.

\section{Conclusion}

The result shows that the use of virtual collaborative environments, technological tools and a collaborative education model can obtain positive results. Usually in the education based on Distance Learning verifies that there is an inconvenient aspect, namely the isolation of the student. However, in this case, where face-toface learning was integrated with the support of the tools, beyond the use of instant messages, this limitation was solved.

The motivation for the massive use of the technology found a good reception, mainly because the students are very young and part of a generation that is very close to the technologies. The introduction of the tools, such as the instant messages programs, with the objective to create learning opportunities allowed to them the perception that the technology can be used with other purposes for which they were not originally created.

The possibility to produce a historical record of the evolution of the learning, as well the process of interaction between the students and between them and the professor, should accompany the results of this work in studying methods of application to other courses.

According to the results observed it can be concluded that the utilization of collaborative and cooperative environment can prepare the students to assume commitments in groups; give and ask for help when it is necessary; offer their individual abilities; create solutions that can benefit everybody; establish goals, task, resources and rules; accept critics; recognize the credits of the other; negotiate; develop interpersonal abilities and familiarize with democratic process of decision taken.

It is interesting to note that the utilization of the "colourful tokens" ranking as well the accompaniment and projects management was efficient to give indicator 
about the project delivery and created an environment of healthy competition to delivery them on time. The goals were to give transparency of the procedures, visibility and to create commitment, which were achieved with success.

The experience shows that the available tools are of easy comprehension and can be used by people with a little technical knowledge in different contexts. Consequently, for a work to obtain a positive result through the use of the information and communication technologies, it is necessary to consider that the work must be cooperative, collaborative and interactive. Cooperative in the sense that if the works are developed in groups to reach common goals. Collaborative through of the exchange of material between the components, and interactive in the sense of the work be integrated, where everybody can interact to occur the significant learning.

To carry out this research of applying technology to the curriculum of the Information Systems course of the Federal University of Acre permitted to elaborate formulations and models and also to take institutional conscience that this process goes beyond learning how simply apply the new technologies in the education. A conscious effort must be made by professors and students to apply and develop researches of the course coordination, instruments and communication channels that can be able to do the management, produce and share information, as well its transformation to produce knowledge in the solving problems of the educational community through projects that can be built in a collective way.

\section{References}

[1] Brito, R. F.; et. al. A study on collaborative environments and their tools. UFSC: Congresso Nacional de Ambientes Hipermídia para Aprendizagem. Florianópolis. 21-24 Jun., 2004.

[2] Turoff, M.; Hiltz, S. R. Computer Support for Group versus Individual Decisions. IEEE Transactions on Communications, 30, pp. 82-91, Jan. 1982.

[3] Bruzzi, D. G. Gerência de Projetos. São Paulo: Érica, 2002.

[4] Cleland, D. I.; Ireland, L. R. Gerência de Projetos. Rio de Janeiro: Reichmann \& Affonso, 2002.

[5] Dinsmore, P. C. Como se tornar um profissional em gerenciamento de projetos. Rio de Janeiro: Qualitymark, 2003.

[6] Heldman, K. Gerência de Projetos: guia para o exame oficial do PMI. Rio de Janeiro: Elsevier, 2003.

[7] Kerzner, H. Gestão de projetos. Porto Alegre: Bookman, 2002.

[8] Maximiano, A. C. A. Administração de Projetos: como transformar idéias em resultados. 2. ed. São Paulo: Atlas, 2002.

[9] Vargas, R. V. Gerenciamento de Projetos. Rio de Janeiro: Brasport, 2003.

[10] Silva, E. L.; Menezes, E. M. Metodologia da pesquisa e elaboração de dissertação. 3. ed. Florianópolis: LED, UFSC, 2001.

[11] Prado, D. Gerência de Projetos em Tecnologia da Informação. 2. ed. Belo Horizonte: EDG, 1999. 